\title{
Da necessidade e dos limites da exposição dialética das categorias da economia política
}

On the need and the limits of the dialectical exposition of the categories of political economy

\author{
Bruno Höfig ${ }^{(1)}$ \\ (1) Universidade de Londres
}

\begin{abstract}
This paper explores the hypothesis that the paradoxical character of the concept of value is behind the need to adopt a dialectical form of exposition of this concept. Building on the works of authors associated with critical theory, it examines value's specific mode of objectivity, and argues that Marx's adoption of the dialectic mode of exposition was motivated by his comprehension that value is at once immaterial and objective. It then analyses the relation between dialectics and critique, and shows that Marx's adoption of the dialectic mode of exposition allows him to both unveil the historicity of value and its forms and to explain why such social entities necessarily appear as something natural. Lastly, it argues that the limits of the capitalist social forms determine the character of their dialectical exposition, which means that the latter has limits of the latter cannot be overcome without deforming the very content of such forms.
\end{abstract}

\section{Keywords}

value theory, method, dialectics, social forms.

JEL Codes B00, B10, B14, B40.

\section{Resumo}

Este artigo explora a hipótese de que o caráter paradoxal do valor obriga a sua exposição conceitual a assumir uma forma dialética. Ele mobiliza reflexões de autores vinculados à teoria crítica com o intuito de desvendar o modo de objetividade específico do valor e mostra que a adoção marxiana do método dialético de exposição é motivada pela compreensão de que o valor é, a um só tempo, algo objetivo e imaterial. $O$ artigo examina a relação entre dialética e crítica, mostrando que o método de exposição adotado por Marx permite a ele revelar a historicidade do valor e de suas formas e explicar por que esses elementos aparecem aos sujeitos como algo natural. Finalmente, argumenta-se que os limites do valor e de suas formas determinam o caráter do método adequado à sua exposição, o qual possui limites que só podem ser ultrapassados sob custo da deformação do seu próprio objeto.

\section{Palavras-chave}

teoria do valor, método, dialética, formas sociais.

Códigos JEL B00, B10, B14, B40. 


\section{Introdução}

"O trabalho de que aqui se trata é o da crítica das categorias econômicas ou, se você preferir, o sistema da economia burguesa apresentado criticamente. É simultaneamente a apresentação do sistema e, através da apresentação, a sua crítica."

Karl Marx. Carta a Lassale (22/02/1858)

Em carta endereçada a Engels, Marx reprova Ferdinand Lassale por aplicar a dialética hegeliana diretamente ao entendimento da economia política. De acordo com Marx (1987 [1858], p. 550, tradução nossa), "ele [Lassale] saberá, para seu prejuízo, que levar uma ciência através da crítica até o ponto em que ela pode ser exposta dialeticamente é uma coisa totalmente diferente de aplicar um sistema abstrato da lógica a tal sistema". A passagem contém ao menos duas informações relevantes para a compreensão do método empregado por Marx na sua apresentação dos conceitos da economia política. Em primeiro lugar, ela sugere que crítica e dialética estão umbilicalmente ligadas: como afirma Grespan (2000, p. 96), Marx indica aqui que "é a crítica que permite à exposição assumir a forma dialética". Em segundo, ela dá a entender que o método dialético adequado à exposição dos conceitos da economia difere de maneira importante da dialética hegeliana: se esta, como se sabe, não admite pressupostos (cf. THEUNISSEN, 1994; 2019), o método a que se refere Marx, pelo contrário, tem na própria crítica o seu pressuposto fundamental.

Note-se, porém, que, na carta em questão, Marx não explica por que exatamente a ciência da economia deve ser criticada, deixando assim sem justificativa o pressuposto de que seria necessário levar tal ciência até o ponto em que ela possa ser apresentada dialeticamente. Além disso, embora fique claro que a exposição dialética dos conceitos da economia política tem pressupostos, o que evidentemente implica que tal modo de exposição deve possuir limites, nada é dito a respeito da natureza e da extensão desses limites. A carta de Marx nos conduz, portanto, a pelo menos duas importantes questões: por que exatamente a exposição dos conceitos da economia política deve ser dialética? E quais são os limites do método a que Marx se refere?

Este artigo contribui para a elaboração de respostas a essas questões. Ele explora a hipótese de que a compreensão da necessidade e do caráter da exposição dialética dos conceitos da economia política depende do reconhecimento do caráter paradoxal de sua categoria fundamental: o valor. 
Como mostra Marx no primeiro capítulo de $O$ capital, o valor é algo a um só tempo objetivo e imaterial:

Em direta oposição à palpável e rude objetividade dos corpos das mercadorias, não se encerra nenhum átomo de matéria natural na sua objetividade de valor. Podemos virar e revirar uma mercadoria, como queiramos, como coisa de valor [Wertding] ela permanece inapreensivel (K, I, 176; C, I.1, 62). ${ }^{1}$

A presente contribuição argumenta que a economia política se mostrou incapaz de lidar com a objetividade "puramente social" (K, I, 62; C, I.1, 54) do valor. Como veremos, em vez de refletir sobre o caráter paradoxal de sua categoria fundamental, ela procedeu por recalcá-lo, ora reduzindo a objetividade de valor das mercadorias a uma de suas determinações materiais, ora confinando o valor no reino da subjetividade. $\mathrm{O}$ artigo mobiliza reflexões de autores vinculados ao que se convencionou chamar de teoria crítica - particularmente, Max Horkheimer e Helmut Reichelt - a respeito do modo de objetividade das formas sociais constitutivas do modo de produção capitalista, com o intuito de lançar luz sobre a abordagem marxiana ao problema do valor. Argumenta-se, por um lado, que a superação do dualismo característico das teorias econômicas do valor é um dos objetivos fundamentais da crítica da economia política; e, por outro, que o método de exposição cumpre um papel crucial na realização desse objetivo. Através de uma análise dos comentários de Marx acerca do método da economia política, mostra-se que, longe de ser arbitrária, a adoção do método dialético em $O$ capital ${ }^{2}$ foi motivada pela compreensão do caráter paradoxal de seu objeto de análise. Examina-se então a conexão entre dialética e crítica na abordagem marxiana, e argumenta-se que o método de exposição adotado por Marx permite a ele não apenas exprimir conceitualmente a determinação social da objetividade do valor, mas também explicar por que essa forma social historicamente determinada inevitavelmente aparece aos indivíduos como natural. Finalmente, demonstra-se que, ao contrário do espírito hegeliano, o valor em processo é constitutivamente incapaz de absorver todos os seus pressupostos, o que por sua vez indica

1 As citações de $O$ capital contidas neste artigo serão acompanhadas de uma dupla referência: a primeira, à edição original contida nos volumes 23, 24 e 25 de Marx und Engels Werke (Marx, 2003, 2004, 2005). A segunda, à edição em português publicada na coleção Os economistas (Marx, 1983a, 1983b, 1985a, 1985b). Quando se julgou conveniente, a tradução das passagens citadas foi alterada.

2 Sobre o caráter dialético do método adotado por Marx, ver o posfácio da segunda edição de $O$ capital (particularmente, K, I, 27; C, I.1, 20). 
que a forma dialética de exposição adequada à crítica da economia política possui limites que só podem ser ultrapassados sob custo de uma deformação do seu próprio conteúdo. $\bigcirc$ artigo se encerra com uma breve análise desses limites.

\section{Da economia política...}

Se dividíssemos toda a economia política de acordo com as duas principais abordagens ao problema do valor, e se identificássemos em Ricardo (1982) e Böhm-Bawerk (1986) dois dos principais representantes dessas abordagens, teríamos diante de nós dois campos que, apesar de suas importantes e irredutíveis diferenças, partilham de uma determinação essencial comum. Como se sabe, o primeiro campo buscou fundamentar a categoria do valor exclusivamente na materialidade do processo produtivo, sem se indispor com as condições subjetivas que tornam possível a redução dos mais variegados produtos a uma forma universal de riqueza. ${ }^{3} \mathrm{O}$ segundo, por sua vez, tentou fundamentar a categoria do valor exclusivamente na estrutura do intelecto humano: na própria medida em que concebem a categoria do valor como uma contrapartida imediata da capacidade humana de abstração e, por conseguinte, como pressuposto da experiência econômica humana em todos os períodos históricos, os proponentes da teoria subjetiva do valor se veem autorizados a ignorar as diferentes condições objetivas sob as quais a faculdade de abstrair perde a forma da pura potência e adquire efetividade. ${ }^{4}$

3 Nada revela melhor esse caráter da teoria ricardiana do valor do que a conhecida quimera do padrão invariável de valor. Cf. Sraffa (1982).

4 Somente assim pode Böhm-Bawerk chamar de capitalista toda atividade produtiva na qual se instalou uma mediação na relação entre a necessidade que a motiva e seu processo de satisfação. Nas palavras do economista austríaco: "a produção, que caminha por sábios caminhos indiretos, não é outra coisa senão aquilo que os estudiosos de Economia Política denominam produção capitalística, da mesma forma que a produção que vai diretamente, usando só as mãos, ao objetivo, é por eles chamada de produção sem capital. Por sua vez, o capital outra coisa não é senão o conjunto dos produtos intermediários que surgem nas diversas etapas individuais que perfazem a via de surgimento indireta" (Böhm-Bawerk, 1986, p. 38). Note-se de passagem que, embora Böhm-Bawerk não o reconheça, deve haver um primeiro momento nessa mediação, que consiste no autorreconhecimento do sujeito do processo produtivo como sujeito. Com efeito, o argumento de Böhm-Bawerk pressupõe um aprendizado proporcionado pela própria prática da produção direta, sem o qual seria impossível ao sujeito transformar seu corpo em instrumento e introduzir um plano no processo produtivo: sem essa mediação, a própria introdução de intermediários materiais no ato produtivo seria im- 
Pode-se dizer então que, do ponto de vista do conteúdo, essas duas abordagens ao problema do valor aparecem como perfeitamente antagônicas. Na medida, porém, em que concebem a relação entre o momento subjetivo e o momento objetivo da constituição do valor sob a forma da dualidade, pode-se dizer também que essas abordagens se reúnem numa verdadeira comunhão formal. $\mathrm{E}$ isso, paradoxalmente, leva-as a coincidir num ponto fundamental: ambas terminam, consciente ou inconscientemente, por conceber o valor como uma categoria trans-histórica. ${ }^{5}$

\section{3 ... à teoria crítica}

Encontramos, nas duas abordagens ao problema do valor desenvolvidas pela economia política, uma característica que Max Horkheimer julgava caracterizar o tipo de pensamento científico que tende a se desenvolver nas sociedades em que vigora o modo de produção capitalista. De acordo com o pensador frankfurtiano, na medida em que "assume toda a natureza humana e sobre-humana como dada" (Horkheimer, 2017 [1937], p. 12, tradução nossa), tal pensamento concebe "o dualismo do pensamento e do ser" como algo "natural" (ibidem, p. 10). Horkheimer enfatiza, porém, que essa abordagem dualista à relação entre realidade e pensamento - à qual se associa uma "hipostasiação do Logos" (ibidem, p. 11) imanente à sociabilidade capitalista - não resulta de uma elaboração consciente e intencional do teórico. Pelo contrário, tal modo de representação da realidade emerge espontaneamente das práticas às quais o indivíduo é induzido pelas relações sociais a que está sujeito. Como afirma Horkheimer, "é, em regra, um traço constitutivo do indivíduo [formado sob condições capitalistas - BH] que as determinações fundamentais de sua existência sejam por ele aceitas como dadas" (ibidem, p. 20), de modo que "o mundo perceptível inteiro, do modo como ele existe para o membro da sociedade burguesa (...) vale [gilt]

possível. Assim, se Böhm-Bawerk estivesse correto, a primeira forma do capital seria, tanto lógica quanto cronologicamente, o capital humano. Essa conclusão necessária da teoria subjetiva do valor, que Böhm-Bawerk não conseguiu reconhecer, foi, no entanto, derivada por seu contemporâneo Irving Fisher (2011 [1906]).

5 Como mostra Backhaus (2002), essa comunhão formal acaba por fazer essas abordagens coincidirem também em seu conteúdo: consciente ou inconscientemente, ambas as abordagens acabam por conceber o valor como uma espécie de grandeza físico-natural. Sobre isso, ver também Heinrich (2014, p. 206, p. 217). 
para o sujeito como a quintessência [Inbegriff] da facticidade: ele está aí e deve ser aceito" (ibidem, p. 12).

Horkheimer enfatiza, porém, que esse modo de representação da realidade possui um caráter ilusório; pois:

As pessoas não são um resultado da história apenas em seu modo de vestir $e$ de se comportar; também o modo como elas veem e ouvem não deve ser descolado do processo histórico vital, como este se desenvolveu por milênios. Os fatos, que os sentidos nos arranjam, são pré-formados socialmente em duplo sentido: por meio do caráter histórico do objeto percebido e do caráter histórico do órgão que o percebe. Ambos são formados não apenas naturalmente, mas também através da atividade humana; o indivíduo, porém, se experimenta a si mesmo na percepção como receptivo e passivo (Horkheimer, 2017, p. 13, tradução nossa).

Eis então que os objetos da experiência não são algo imediato; pelo contrário, eles são condicionados pelas faculdades do sujeito que os percebe. De acordo com Horkheimer, porém, tais faculdades são também algo mediado: assim como o objeto percebido, o órgão que o percebe é formado "não apenas naturalmente, mas através da atividade humana". Note-se, todavia, que a própria atividade humana é por sua vez determinada por um outro: como nota Reichelt (2008, p. 19), a ação individual é "estruturalmente mediada", pois condicionada pelas relações sociais que os seres humanos (seres inevitavelmente sociais) contraem entre si em determinado período histórico. ${ }^{6}$ E isso nos leva a concluir que, apesar das aparências, os fatos não são incondicionados; muito pelo contrário: como sugere Horkheimer, eles são pré-formados socialmente.

Infere-se daí que a sociabilidade característica do modo de produção capitalista possui o poder de constituir a estrutura da consciência individual: através dos modos de atividade que induzem o sujeito a realizar, as relações sociais capitalistas engendram as categorias através das quais o indivíduo representa a realidade. Noutras palavras, as categorias não possuem um caráter transcendental; pelo contrário, elas são sempre "algo mediado [ein Vermmiteltes]" (Reichelt, 2008, p. 36). Isso significa que as formas de objetividade com as quais o sujeito se depara na superfície do modo de produção capitalista - as quais, como afirma Reichelt (2008, p. 36), "aparece[m] ao indivíduo como algo incondicionado [ein Erstens]" são, "até mesmo na experiência individual [Einzeldatum], algo derivado e

6 "Os homens fazem a sua própria história; contudo, não a fazem de livre e espontânea vontade, pois não são eles quem escolhem as circunstâncias sob as quais ela é feita, mas estas lhes foram transmitidas assim como se encontram." (Marx, 2011, p. 25). 
secundário". Elas devem, portanto, ser concebidas não como algo natural, mas como um produto histórico.

Faz-se necessário, portanto, denunciar a aparência de naturalidade que adere tanto às formas de objetividade quanto à forma de subjetividade que se constituem através do modo especificamente capitalista de sociabilidade. E isso só poderá ser feito por aquilo que Horkheimer chamou de teoria crítica: uma teoria que reconhece a inalienável "condicionalidade social" (Horkheimer, op. cit., p. 21) de toda experiência humana - e é, por conseguinte, capaz de superar a abordagem dualista que caracteriza o pensamento científico acrítico.

\section{A objetividade imaterial do valor e a tarefa da teoria crítica}

Essas considerações nos levam em direção a uma trilha aberta por Marx em sua crítica da economia política. Como se sabe, Marx afirmava que "as categorias [econômicas] exprimem formas de ser-aí [Daseinformen], determinações da existência [Existenzbestimmungen]" (Marx, 1974, p. 40; ver também Marx, 1972, p. 126). Com efeito, em O capital, Marx mostra que um produto do trabalho não é naturalmente coisa de valor; pelo contrário, apenas na medida em que é produto "de trabalhos privados autônomos e independentes entre si" (K, I, 57; C, I.1, 171) uma coisa passa a ser, além de um valor de uso, um valor (K, I, 55; C, I.1, 170). Noutras palavras, o valor é uma forma de objetividade que só adere à riqueza material quando esta é produzida para a troca: nas palavras de Marx, "somente dentro de sua troca os produtos do trabalho recebem uma objetividade-de-valor socialmente igual, separada da sua objetividade de uso fisicamente diversa" (K, I, 87; C, I.1, 199).

Eis então que o valor é uma forma de objetividade social e historicamente determinada: como afirma Marx, o valor e as formas dele derivadas (das quais trataremos a seguir) "constituem (...) as categorias da economia burguesa" única e exclusivamente porque são "formas socialmente válidas

[gültige] e, portanto, objetivas para as relações de produção desse modo social de produção historicamente determinado, a produção de mercadorias" (K, I, 90; C, I, 1, 201, grifo nosso).

Note-se, porém, que, ao indivíduo cuja sociabilidade é mediada pela relação de troca, a coisa se apresenta de modo completamente invertido. 
À medida que os sujeitos desempenham suas atividades econômicas como agentes privados, a rede de relações sociais que integra suas atividades isoladas à divisão social do trabalho passa necessariamente a se lhes apresentar como algo exterior, isto é, como um mero pressuposto de sua experiência e de seu agir. E, à medida que tais relações se apresentam unilateralmente como um pressuposto de toda experiência e de toda ação social, o indivíduo passa irrefletidamente a adequar seus atos às formas de racionalidade a elas associadas (Heinrich, 2014, p. 207), num processo de adaptação cujo resultado é a reprodução do próprio regime de normatividade característico do modo de produção capitalista.

Em sua perplexidade, pensam os nossos possuidores de mercadorias como Fausto. No começo era a ação. Eles já agiram, portanto, antes de terem pensado. As leis da natureza das mercadorias atuam no instinto natural dos seus possuidores (K, I, 101; C, I.1, 211).

Existe, então, no modo de produção capitalista, um tipo peculiar de conexão entre ato e estrutura, o qual determina o caráter aparentemente intocável da rede de relações constitutivas desse modo de organização da vida material da humanidade. E isso, para nós, é crucial. Pois, na própria medida em que adéquam suas ações às normas reguladoras impessoais instituídas pelas relações sociais que constituem o modo de produção capitalista, os indivíduos inconscientemente produzem e reproduzem não apenas essas relações, mas também as formas de objetividade delas derivadas:

Eles não o sabem, mas o fazem (...) Esta é uma operação instintiva espontânea $e$, portanto, inconsciente de seu cérebro, que emerge necessariamente do modo peculiar de sua produção material e das relações nas quais essa produção os empenha (Marx, 1867, p. 38, tradução nossa).

Eis então que as forma de objetividade que emergem exclusivamente nas sociedades em que predomina o modo de produção capitalista tendem a aparecer não como resultado das ações historicamente determinadas dos sujeitos, mas antes como dados naturais. E isso significa que a "diferenciação entre sujeito e objetividade" se apresenta, aos indivíduos cuja integração à divisão social do trabalho se dá através da relação de troca, "na forma do em-si" (Reichelt, 2008, p. 25). Com efeito, embora o valor seja uma forma de objetividade que só emerge sob condições capitalistas, a riqueza material parece, aos agentes cuja sociabilidade se dá sob tais condições, ser em si mesma coisa de valor (K, I, 87; C, I.1, 199); e isso, como nota Reichelt (2008, p. 25), faz com que a estrutura da sua consciência e a forma da sua 
subjetividade apareçam aos sujeitos como algo natural - do que se segue que as categorias que caracterizam exclusivamente as formações sociais capitalistas inevitavelmente aparecem, aos indivíduos que pertencem a tais formações, como categorias válidas a priori.

Ora, se é assim, então as insuficiências das teorias econômicas do valor - as quais, como vimos, oscilam entre a redução do valor às determinações materiais das mercadorias e o confinamento dessa categoria no reino da subjetividade transcendental - não resultam de um mero equívoco conceitual. Pelo contrário, a oposição entre formas de objetividade e subjetividade, isto é, entre sujeito e objeto da experiência econômica, é o resultado necessário do modo de sociabilidade característico da economia capitalista: na medida em que a totalidade social criada pelos indivíduos se apresenta como o pressuposto inconsciente de suas ações, as categorias com as quais eles orientam suas ações aparecem sempre como um dado, portanto, como o pressuposto da ação racional enquanto tal. E isso significa que a dualidade do sujeito e do objeto não é uma criação arbitrária do economista, mas antes a forma fenomenal necessária da unidade formada pelas estruturas de objetividade e subjetividade constitutivas do modo de produção capitalista, uma unidade na qual os criadores, em função do próprio modo como a criam, tornam-se incapazes de reconhecer sua criatura.

O teórico da economia capitalista encontra-se, portanto, diante de um paradoxo. Como, porém, não se trata de um mero paradoxo da teoria, mas de um "paradoxo da [própria] realidade efetiva [Wirklichkeit]" (Marx, 2008a, p. 134), o analista que decidir simplesmente ignorá-lo será inevitavelmente levado a cair em contradição (Backhaus, 2002). Certo, em função do próprio isolamento a que estão confinados por um modo de produção cuja relação social fundamental é a troca, os sujeitos são levados a representar e experimentar as relações e formas constitutivas desse mesmo modo de produção como entes autônomos e naturais. Isso, todavia, não significa que o teórico deva simplesmente ignorar o fato de que - como afirma Wolf (2017, p. 1, grifos no original, tradução nossa) - "são as próprias pessoas quem, das estruturas mais simples às mais complexas dessa sociedade, as criam e configuram". Muito pelo contrário: o que isso significa é que uma teoria adequada ao modo de produção capitalista deve ser capaz, a um só tempo, de demonstrar a necessidade da dualidade do sujeito e do objeto e de superá-la conceitualmente. Trata-se, portanto, de revelar que as formas de objetividade e subjetividade que determinam o conteúdo das 
ações individuais nas sociedades em que predomina o modo de produção capitalista são também o produto inconsciente dessas mesmas ações. Eis a tarefa da crítica da economia política.

\section{A ascensão do abstrato ao concreto}

A pretensão de superar conceitualmente o dualismo do sujeito e do objeto cria consideráveis dificuldades metodológicas. Não podendo pressupor a validade do conceito de valor, o teórico se verá diante da necessidade de provar que as relações sociais e o arcabouço categorial característicos do modo de produção capitalista constituem um todo orgânico. Mas, se essas relações e categorias formam um todo orgânico, então por onde se deve começar? Como, apesar do caráter necessariamente linear da exposição textual, apresentar conceitualmente um objeto não linear?

À resolução desse problema servirá aquilo que ficou conhecido como o método da ascensão do abstrato ao concreto, um método lógico-sistemático que pretende expor não o movimento histórico do capital propriamente dito, mas sim a auto-organização interna do sistema socioeconômico cuja forma fundamental é o valor (Marx, 1974, p. 41). Em tal movimento expositivo, reconstitui-se conceitualmente a rede de relações sociais - e, simultaneamente, das formas de objetividade que lhes correspondem - através das quais a lei do valor se impõe sobre a vida das mulheres e dos homens que, por meio de suas ações imediatamente conscientes, inconscientemente produzem e reproduzem essa mesma rede de relações.

Tal método é descrito por Marx na famosa Introdução de 1857:

Quando estudamos um dado país do ponto de vista da Economia Politica, (...) parece que o correto é começar pelo real [Real] e concreto, que é o pressuposto efetivo [wirkliche]; assim, em Economia, por exemplo, começar-se-ia pela população, que é o fundamento [Grundlage] e o sujeito do ato social de produção como um todo. No entanto, numa observação mais atenta, isso se mostra falso. A população é uma abstração [Abstraktion], se desprezarmos, por exemplo, as classes que a compõem. (...) Assim, se começássemos pela população, teríamos uma representação caótica do todo [Ganze], e através de uma determinação mais precisa chegaríamos analiticamente a conceitos cada vez mais simples; do concreto representado passaríamos a abstrações [Abstrakta] cada vez mais tênues até atingirmos as determinações mais simples. Desse ponto, teríamos que voltar a fazer a viagem de modo inverso, até chegarmos finalmente de volta à população; dessa vez, porém, não como representação caótica de um todo, mas como uma rica totalidade [Totalität] de muitas determinações e relações. (...) $O$ concreto é concreto porque é a sintese de muitas determinações, isto é, unidade 
do diverso. Por isso o concreto aparece no pensamento como processo da sintese, como resultado, não como ponto de partida, ainda que seja o ponto de partida efetivo e, portanto, o ponto de partida também da intuição e da representação. No primeiro trajeto, a representação plena foi volatilizada em determinações abstratas; no segundo, as determinações abstratas conduzem à reprodução do concreto no trajeto do pensamento. (...) o método de se elevar do abstrato ao concreto é apenas a maneira de proceder do pensamento para se apropriar do concreto, reproduzi-lo como concreto espiritual (Marx, 1985c, p. 116-117).?

Eis então que o método "cientificamente correto", o qual nos permite reproduzir no pensamento aquilo que a experiência imediata nos deixa apreender apenas de modo caótico, deve distinguir três tipos de concretude: tem-se, em primeiro lugar, o real-concreto (das Real), i.e. o empírico, ponto de partida de toda intuição e toda representação e, como tal, pressuposto efetivo de toda ciência; em segundo, o concreto representado, i.e. o concreto reproduzido pela consciência imediata através de categorias que a análise mais atenta revela serem ainda meras abstrações (pois indeterminadas); e, por fim, o concreto "como processo de síntese, como resultado, não como ponto de partida": um concreto que "[n]ão é mais individual, mas sim um todo, uma totalidade; que não mais exprime momentos isolados apreendidos pelos sentidos [Sinnlichkeit], mas sim a conexão" (Sgro', 2009 , p. 205) entre seus momentos.

Deve-se, portanto, reconhecer, por um lado, que a sociedade capitalista "permanece subsistindo, agora como antes, em sua autonomia fora do cérebro", e que "o método de se elevar do abstrato ao concreto é apenas a maneira de proceder do pensamento para se apropriar do concreto, reproduzi-lo como concreto espiritual"; e, por outro, que essa "apropriação do concreto" não pode se dar através do espelhamento imediato do concreto pela representação, mas apenas como síntese, como resultado de uma reconstrução a partir das categorias mais simples e gerais, nas quais se exprimem as abstrações efetivas (Abstrakta) ${ }^{8}$ a que chegamos pela análise do real-concreto, e que devem ser distinguidas da má abstração (Abstraktion) a que é conduzido o pensamento quando procura teorizar diretamente sobre a realidade imediata. O concreto a que assim somos levados "é a síntese de muitas determinações, isto é, unidade do diverso", 9 resultado de

7 Tradução alterada com base em Marx (1974, p. 34-36).

8 Essa abstração efetiva é o valor, isto é, o valor como "valor-capital em processo [prozessierende]", o qual Marx concebe como uma "abstração in actu" (K, II, 106-110).

9 Note-se que o termo "concreto" deriva-se do verbo latino concrescere, cujo significado é "crescer junto". 
um movimento do pensamento que "expõe progressivamente, a partir das determinações mais simples e abstratas do conteúdo, suas determinações cada vez mais ricas, complexas e intensas, até o ponto de sua unidade, que não é uma unidade formal, mas uma unidade sintética de múltiplas determinações" (Müller, 1982, p. 23).

Assim, o método proposto deve ser constituído por dois momentos distintos e complementares: no primeiro, a faculdade da abstração nos leva "do concreto representado" até "as determinações mais simples"; no segundo, faz-se a viagem de "modo inverso, até chegarmos finalmente" ao concreto, "dessa vez, porém, não como representação caótica de um todo, mas como uma rica totalidade de muitas determinações e relações". Nas palavras de Marx citadas anteriormente: "no primeiro trajeto, a representação plena foi volatilizada em determinações abstratas; no segundo, as determinações abstratas conduzem à reprodução do concreto no trajeto do pensamento". São trajetos distintos, pois enquanto no primeiro deles se trata de pesquisar o material, no segundo trata-se de expô-lo, apresentá-lo da maneira adequada; e complementares, porque a exposição adequada, único modo de reproduzir racionalmente o concreto, tem sempre a pesquisa como seu pressuposto. Como formularia Marx em $O$ capital:

A pesquisa tem de captar detalhadamente o material, analisar as suas várias formas de desenvolvimento e rastrear seu nexo interno [innres Band]. Só depois de concluido esse trabalho é que o movimento efetivo [wirkliche] pode ser adequadamente apresentado. Caso se consiga isso e a vida do material se reflita agora idealmente, então pode parecer que se trata de uma construção a priori $(K, I, 27 ; C, I .1,140)$.

"O modo de exposição [Darstellungsweise]" deve então ser distinguido "do modo de pesquisa" (K, I, 27; C, I.1, 140). Essa distinção, porém, deve ser feita apenas "formalmente" (K, I, 27; C, I.1, 140); pois, como veremos a seguir, a exposição será ela mesma condicionada pelas determinações desveladas pela análise do objeto.

\section{As insuficiências da economia política}

Marx negava à maior parte da teoria econômica o estatuto de ciência: porque ela se recusa a investigar as representações dos agentes imersos na sociabilidade capitalista, limitando-se a espelhá-las, aquilo que ele chamava de economia vulgar abandona desde o início o método adequado ao raciocínio 
científico propriamente dito. Noutras palavras, a economia vulgar apenas reflete imediatamente as formas de aparecimento das relações sociais de produção, sem atentar para sua conexão interna (K, III, 822-839; C, III.2, 269-280), e é por isso que suas apreensões teóricas da realidade capitalista são inevitavelmente autocontraditórias e insuficientes do ponto de vista científico.

Como, contudo, dizer o mesmo da economia clássica? Como alegar, por exemplo, que ela ignora que "na aparência [Erscheinung] as coisas frequentemente aparecem de modo invertido" (K, I, 559; C, I.2, 169) se, de acordo com o próprio Marx, seu "maior mérito" foi justamente "ter dissolvido [a] aparência (...) [de] autonomização dos diferentes elementos sociais da riqueza" (K, III, 838; C, III.2, 280) e considerado "corretamente o valor e a relação do lucro, do salário etc. como parte desse valor" (Marx, 2008b, p. 100)? Para responder a essas perguntas, será útil recorrer a um importante comentário a respeito da obra de Ricardo. Segundo Marx, o economista inglês:

\begin{abstract}
abstrai com consciência da forma da concorrência, da aparência da concorrência, com o intuito de considerar a lei enquanto tal. Por um lado deve-se the censurar pelo fato de que ele não vai longe o suficiente na abstração, não está de todo na abstração - assim, por exemplo, quando ele considera o valor da mercadoria, mas já se deixa determinar pela consideração de todo tipo de relações concretas; por outro lado, que ele considera então a forma de aparecimento imediatamente, diretamente como comprovação ou apresentação da lei geral, de modo algum a desenvolve. No que diz respeito ao primeiro [ponto] é sua abstração muito incompleta, quanto ao segundo é ela abstração formal, a qual é, em si e para si, falsa (Marx, 2008b, p. 100, tradução nossa).
\end{abstract}

Assim, se Ricardo "abstrai da forma da concorrência", ele "não vai longe o suficiente nessa abstração". Consequentemente, apesar de chegar ao trabalho como substância do valor, ele é incapaz de ver que "o trabalho que põe [setzende] valor (...) é uma forma especificamente social de trabalho" (Marx, 1971, p. 24): o trabalho abstrato; que apenas na sociedade em que se produz predominantemente para a troca o valor aparece como "forma imediatamente social" (K, I, 91; C, I.1, 203) dos produtos do trabalho; e que, portanto, longe de ser a forma natural desses, a mercadoria só se apresenta como forma elementar da riqueza no modo de produção capitalista (K, I, 49; C, I.1., 165) - o qual, por conseguinte, deve ser compreendido como um modo de produção historicamente determinado.

Como diz Marx em O capital, embora tenha analisado, "ainda que incompletamente, valor e grandeza de valor e o conteúdo oculto nessas formas", a economia clássica "nunca chegou a perguntar por que esse conteúdo assume aquela forma, por quê, portanto, o trabalho se representa pelo 
valor e a medida do trabalho, por meio de sua duração, pela grandeza do valor do produto de trabalho" (K, I, 94; C, I.1, 205).

É uma das falhas básicas da Economia Política clássica não ter jamais conseguido descobrit, a partir da análise da mercadoria e, mais especialmente, do valor das mercadorias, a forma-valor, que justamente o torna valor de troca. Precisamente, seus melhores representantes, como A. Smith e Ricardo, tratam a forma-valor como algo totalmente indiferente ou como algo externo à própria natureza da mercadoria ( $K, I, 95 ; C, I .1,205-206)$.

Noutras palavras, a economia política clássica:

não investiga de modo algum o valor segundo sua forma - a forma determinada que o trabalho assume como substância do valor -, mas apenas as magnitudes de valores, as quantidades desse trabalho [que é] universalmente abstrato e social graças a essa forma, que produz a diferença nas quantidades de valor das mercadorias (Marx, 2008b: 163, grifos e tradução nossos).

Assim, o trabalho de abstração da economia clássica é incompleto porque, ao chegar à categoria mais geral da economia capitalista, ela se mostra incapaz de reconhecê-la como forma social (e, portanto, histórica), uma forma determinada assumida pelo produto do trabalho quando este se socializa através da relação de troca (K, I, 93; C, I.1, 205-206, nota). Não à toa, ela não consegue compreender as formas imanentes ao modo de produção capitalista como formas sociais, o que a condena a assumir aprioristicamente a validade de categorias cuja validade se restringe a um modo específico de organização da produção social. Assim:

mesmo seus melhores porta-vozes, como não poderia ser diferente do ponto de vista burguês, permanecem mais ou menos presos ao mundo da aparência [Schein] que sua crítica extingue; por isso, todos eles recaem, em maior ou menor grau, em formulações inconsequentes, semiverdades e contradições não-solucionadas (K, III, 838; C, III.2, 280).

"Como", porém, "esse ponto é o ponto crucial em torno do qual gira a compreensão da Economia Política" (K, I, 56; C, I.1, 171), Marx se vê obrigado a dedicar as primeiras páginas de sua principal obra à conclusão crítica do trabalho de análise que a economia clássica deixara incompleto, ${ }^{10} \mathrm{e}$ a mostrar que a mercadoria não é valor de uso e valor de troca, mas valor de uso e valor, e que "o trabalho, à medida que é expresso no valor, já não possui as mesmas características que lhe advêm como produtor de valores de uso" (K, I, 56; C, I.1, 171).

Somente depois disso poderá Marx iniciar o trabalho de apresentação do material pesquisado, dando início ao segundo momento do "método 10 "Nossa investigação começa (...) com a análise da mercadoria" (K, I, 49; C, I.1, 165). Cf. Rubin (2008, cap. 8). 
cientificamente correto". Note-se, porém, que também aqui será necessário superar Ricardo. O economista inglês, afinal, não apenas deixou incompleto o trabalho de análise, mas também cometeu o equívoco de considerar "a forma de aparecimento imediatamente, diretamente como comprovação ou apresentação da lei geral" - quando, na verdade, seria necessário "desenvolver" essa "forma de aparecimento" a partir daquela "lei":

[E]m Ricardo, a unilateralidade vem de ele querer em geral demonstrar que as diversas categorias ou relações econômicas não contradizem a lei do valor, em vez de, ao contrário, desenvolvê-las junto com suas contradições aparentes a partir desse fundamento ou expor o desenvolvimento desse fundamento mesmo (2008b, p. 146, grifo e tradução nossos).

Ricardo erra, portanto, ao aceitar as diversas categorias econômicas, tais como elas se apresentam no plano da empiria, como aptas à constituição científica do objeto, ou seja, ao pressupô-las como dadas, em vez de desenvolvê-las a partir de seu fundamento social: a forma do valor. Tal resultado, cabe notar, nada tem de casual. Como afirma Reichelt (2008, p. 426, tradução nossa):

As categorias não devem ser apreendidas de modo exterior e absolutizadas como naturais; trata-se pelo contrário de desenvolvê-las geneticamente, como formas historicamente devindas, as quais, enquanto socialmente condicionadas, podem também novamente desaparecer com a sociedade da qual nasceram.

E se, como o mesmo Reichelt assevera (1973, p. 127, tradução nossa), "um método que apreende as categorias de modo exterior deve necessariamente conduzir a um modo falso de exposição [Darstellungsart] do processo total", então, não nos deve surpreender que a insuficiência da análise de Ricardo esteja associada a um modo também insuficiente de apresentação do material analisado. Na medida em que pressupõe acriticamente a validade das categorias da economia política, o economista inglês é inevitavelmente levado a ignorar o fato de que as formas e relações econômicas mais concretas só adquirem validade científica quando são desenvolvidas conceitualmente, e não apanhadas diretamente da empiria.

\section{A exposição dialética das categorias}

Como foi dito anteriormente, o modo de apresentação pode ser distinguido do modo de pesquisa apenas formalmente. Tudo leva a crer então que as duas falhas metodológicas de Ricardo - a insuficiência de seu trabalho 
de abstração (análise) e o não desenvolvimento das categorias a partir de seu "fundamento contraditório" (síntese) - estão intimamente relacionados, ou seja, que a apresentação equivocada das categorias por parte de Ricardo decorre necessariamente do fato de que ele não reconhece o caráter específico de seu conteúdo (Reichelt, 1973, p. 128). E é isso mesmo o que ocorre: na medida em que não consegue apreender a mercadoria como forma historicamente determinada do produto do trabalho e o valor como a forma sob a qual esse produto se socializa no modo de produção capitalista, ele também não pode perceber o caráter contingente dessas formas - o que por sua vez, impede-lhe de reconhecer a reprodução da sociedade produtora de mercadorias como problema. ${ }^{11}$

A crítica da economia política, pelo contrário, sabe que essas categorias são as "forma[s] estranhada[s] [entfremdet] de aparecimento das relações econômicas" (K, III, 825; C, III.2, 271) de uma sociedade historicamente determinada. Ela consegue, assim, livrar-se da assunção da validade a priori dessas categorias, o que lhe permite reconhecer que a reprodução material da sociedade em que tais categorias adquirem validade nada tem de natural ou trivial. Daí que o movimento conceitual empreendido por Marx possa partir da constatação (analítica) de que "a riqueza das sociedades em que domina o modo de produção capitalista" - um modo de produção que efetivamente existe e, portanto, se reproduz - tem a mercadoria individual "como sua forma elementar" (K, I, 49; C, I.1, 165) e mostrar, a partir daí, como é possivel que isso ocorra (Heinrich, 2014, p. 208) - para o que terá que derivar as relações sociais e, concomitantemente, as formas de objetividade necessárias à existência e à reprodução de uma economia assim organizada. Marx pode, pois, censurar a economia política por pressupor aquilo que deveria desenvolver (Marx, 1974, p. 327): as relações e formas sociais sem as quais a subordinação do metabolismo social à lei do valor seria impossível.

Caberá então à crítica da economia política problematizar pela primeira vez o processo de reprodução material de uma formação social que organiza a produção e a distribuição de valores de uso através da lei do valor - e cujos membros, portanto, devem ser capazes de se reproduzir materialmente apesar de produzirem não para o consumo, mas para a troca tradução nossa). 
(Rubin, 2008, p. 70). Para que tal processo se realize, a contradição contida na mercadoria terá que ser simultaneamente superada e conservada: superada, pois numa economia capitalista o valor de uso de um bem só se realiza quando este se realiza como valor, e vice-versa; conservada, porque uma sociedade em que tal contradição seja abolida não será mais capitalista. Analogamente, o desenvolvimento conceitual empreendido por Marx se configurará como um processo de derivação das formas sociais através das quais a lei do valor pode se realizar (Reichelt, 1973, p. 173178), isto é, das relações sociais específicas através das quais a oposição entre valor de uso e valor poderá se mover: resolver-se e desdobrar-se. Daí que o modo de exposição das categorias da economia deva ser capaz de realizar o processo conceitual de desenvolvimento das contradições da mercadoria a partir dessa contradição fundamental. Trata-se, então, de um modo de exposição cujo motor é a contradição: um modo de exposição dialético (Müller, 1982).

O modo de exposição correto é condicionado, portanto, pelo fato de que, numa sociedade de produtores privados, a atividade produtiva imediata só pode ser integrada à divisão social do trabalho mediatamente. Enquanto unidade imediata do valor de uso e do valor, a mercadoria é uma contradição (Marx, 1971, p. 28, 36); e essa contradição, como mostra Marx (1971, p. 30), precisa se desenvolver e resolver, "produz[indo] uma duplicação da mercadoria em mercadoria e dinheiro, uma oposição externa, na qual ela [a mercadoria - $\mathrm{BH}$ ] apresenta sua oposição imanente entre valor de uso e valor" (K, I, 119; C, I.1, 228).

A forma do dinheiro, cabe notar, "não supera [aufhebt] essas contradições", mas apenas "gera a forma dentro da qual elas podem mover-se" (K, I, 118; C, I.1, 227); e isso significa que, no equivalente geral, encontramos uma forma do valor na qual a oposição constitutiva da mercadoria pode ser ao mesmo tempo resolvida e desdobrada, mas não abolida. Se não abole a contradição, porém, o dinheiro a repõe num nível mais concreto, isto é, um nível que reúne em si mais determinações do que aquele no qual o movimento conceitual se iniciara. E isso mostra que o movimento dialético de exposição tem um sentido exato: ele parte da forma "mais geral e abstrata" em direção às "mais complexas e concretas". O movimento que efetua a resolução e a reposição da contradição entre valor de uso e valor na mercadoria delineia, então, o trajeto que constitui o segundo momento do método "cientificamente correto": aquele que se eleva 
do abstrato ao concreto, constituindo, nas palavras de Marx "a maneira de proceder do pensamento para se apropriar do concreto, reproduzi-lo como concreto espiritual". Como afirma Grespan (2012, p. 34), a exposição categorial deve:

reconstituir a articulação entre os vários aspectos deste conceito como um desdobramento de etapas ou momentos - as "determinidades formais econômicas" -, desdobramento através do qual a definição de "capital" se enriquece progressivamente até alcançar seu conteúdo mais complexo, mais "concreto", num movimento que tem como finalidade apreender a relação entre o "nexo interno" do objeto e suas formas externas de manifestação como uma dedução de categorias.

Ora, esse desenvolvimento expositivo conclui-se apenas quando se chega novamente às formas mais concretas encontradas na superfície da economia capitalista, isto é, quando tais formas são finalmente expostas como formas derivadas do valor. Daí que o último tomo de $O$ capital trate justamente:

de encontrar e expor as formas concretas que emergem do processo de movimento do capital, considerado como um todo. Em seu movimento efetivo [wirklich], os capitais se defrontam em tais formas concretas, para as quais a figura do capital no processo de produção direto, bem como sua figura no processo de circulação, só aparecem como momento particular. As configurações do capital, como as desenvolvemos neste livro, aproximam-se, portanto, passo a passo, da forma em que elas se encontram na superficie da sociedade, na ação dos diferentes capitais entre si, na concorrência e na consciência costumeira dos agentes da produção (K, III, 33; C, III.1, 23).

\section{0 método dialético e a desnaturalização das formas sociais capitalistas}

Vimos que a exposição conceitual empreendida por Marx compreende, a um só tempo, a gênese da forma de consciência burguesa a partir da totalidade das relações sociais constitutivas do modo de produção capitalista e a gênese desta última a partir daquela forma de consciência. Ainda mais: vimos que a aceitação acrítica da dualidade sujeito/objeto se replica, na consciência individual, na naturalização do valor e das formas dele derivadas. A superação conceitual dessa dualidade, por sua vez, revelou o caráter necessário da oposição efetiva entre sujeito e objeto nas sociedades em que a forma mais geral da sociabilidade é dada pela relação de troca: nessas sociedades, as relações econômicas aparecem ao sujeito como algo que lhe é exterior. Porque os dois polos (sujeito e objeto) se encontram efetivamente cindidos na realidade fenomênica, essas relações 
aparecem para o sujeito como um dado, algo exterior a sua existência, e não um produto de seu agir; e, na medida em que seu agir necessariamente pressupõe tais relações, o indivíduo, mesmo onde ele parece agir exclusivamente de modo voluntário e consciente, como na relação de compra e venda, está de fato sujeito às normas de racionalidade que lhe são impostas por tais relações, as quais determinam as próprias categorias com as quais ele representa e orienta seu agir. Por isso, nas sociedades em que predomina o modo de produção capitalista, o sujeito age de maneira a um só tempo consciente e inconsciente. E é isso o que faz com que, nessas sociedades, a vida humana venha a ser regida por um regime normativo que se lhe aparece como exterior: a assim chamada lei do valor. Com efeito, um dos grandes méritos da crítica da economia política foi ter demonstrado, através da supressão conceitual da dualidade sujeito/objeto, que a oposição efetiva entre esses dois polos não pode ser superada dentro do modo de produção capitalista - com o que ela revela simultaneamente a falsidade e a necessidade da aparência de naturalidade das categorias da economia política.

Em função da aparência necessária de naturalidade das formas capitalistas, bem como da falsidade dessa aparência, os conceitos da economia política só poderão ser apresentados de modo racional se o forem criticamente, ou seja, se sua exposição for também a exposição de seus pressupostos, a revelação da historicidade de suas determinações e, portanto, também a demonstração de seus limites. Uma vez que o objeto mesmo não é natural, mas aparenta sê-lo, ele só pode ser apresentado racionalmente de modo crítico. Não por acaso, a crítica da economia política possui, simultaneamente, um caráter positivo e negativo: sua precisão científica repousa no reconhecimento da negatividade essencial do capital - reconhecimento que, por seu turno, constitui o primeiro passo para a superação efetiva de seu "mundo encantado" (K, III, 838; C, III.2, 280).

Segue-se que a superação meramente conceitual da dualidade sujeito/ objeto não promove a reconciliação entre esses dois polos: ao contrário do que pretendia Hegel (2005), a supressão dessa dualidade não nos leva ao reconhecimento de uma identidade primordial, mas antes ao desvelamento da violência contida em toda identificação forçada do sujeito a uma objetividade social que ele criou, mas não consegue controlar. $\mathrm{Na}$ medida em que revela que o fetichismo do valor e de suas formas não constitui uma mera loucura individual, mas um produto necessário das formas de 
sociabilidade características das sociedades produtoras de mercadorias, a superação teórica da dualidade demonstra que um dos polos dessa relação reiteradamente, e de modo inconsciente, se adéqua ao outro, conformando-se e deixando-se deformar. A crítica da economia política revela, assim, que a vida social tende, sob condições capitalistas, a se reproduzir de acordo com uma norma reguladora que inevitavelmente se autonomiza frente a seus criadores. A lei do valor estará em vigor enquanto os indivíduos se conformarem a ela, e os indivíduos tendem a se conformar a ela enquanto ela estiver em vigor: ao evidenciar a verdade dessa proposição, a crítica da economia política nos convida a quebrar o encanto.

\section{Os limites da exposição dialética}

Dissemos na última seção que o desenvolvimento lógico-sistemático das formas sociais constitutivas do modo de produção capitalista deveria revelar os pressupostos da lei sob a qual este opera. O leitor já terá notado, porém, que tal asserção recebeu então um caráter arbitrário, já que ali ela não foi provada. Porque esse ponto é de crucial importância para a crítica da economia política, a ele nos dedicaremos nesta seção.

Já vimos que a dialética não possui o estatuto de um método válido em si e por si: a exposição só poderá assumir tal forma se assim exigir o material analisado. Ora, se a forma da exposição é determinada por seu objeto, então os pressupostos sobre os quais este se apoia, caso existam, devem aparecer como limites ao próprio desenvolvimento do conceito; afinal, no(s) ponto(s) onde o valor deve se apoiar em algo que lhe é exterior, a sua exposição não mais poderá prosseguir de modo estritamente dedutivo. Mas tais pontos existem?

A julgar pelas palavras de Marx, a resposta a essa questão é inequívoca: como ele afirma num importante manuscrito, "a forma dialética de exposição é correta apenas quando conhece seus limites" (Marx, 1974, p. 945; grifo nosso, tradução nossa). De fato, a exposição lógico-sistemática do valor só é plausível em função da existência de um modo de organização econômica particular, na qual o trabalho "põe valor" - algo que, como vimos, nada tem de natural. E isso significa que a exposição conceitual propriamente dita pressupõe: 
o diagnóstico histórico de uma sociedade cujas relações sociais de produção estão dominadas por um universal que se auto-adjudica uma subjetividade pseudo- concreta às expensas da atividade concreta dos individuos reais: o capital enquanto valor que se autovaloriza, princípio determinante da reprodução material de uma sociedade que repõe todas as suas condições históricas e lógicas como momentos internos da sua reprodução (Müller, 1982, p. 33).

Ora, tais condições só são encontradas ali onde se generaliza a separação entre o produtor direto e as condições objetivas de realização de sua atividade, "separação (...) [que] consolida a dissolução dos laços orgânicos do indivíduo trabalhador com a comunidade na qual ele se inseria como proprietário e instaura a sua individualidade nua, despojada da propriedade" (Marx, 1974, p. 375, tradução nossa). A constituição histórica do indivíduo enquanto livre da apropriação alheia e da propriedade dos meios de produção, ou seja, a emergência histórica do trabalhador assalariado constitui então o pressuposto histórico e sistemático da autonomização dos meios de produção sob a forma do capital e, portanto, da redução do trabalho concreto a trabalho abstrato e da transformação dos produtos do trabalho em valores (Müller, 1982, p. 33).

Não por outra razão, a crítica da economia política reconhece as dificuldades que a passagem da forma do dinheiro à forma do capital impõe ao desenvolvimento conceitual, e admite que a entrada do trabalhador livre no palco da história não pode ser simplesmente derivada das determinações da circulação simples de mercadorias (K, I, 181-2; C, I.1, 285). ${ }^{12}$ Muito pelo contrário, a relação de capital deverá ser pressuposta em seu surgimento histórico (Müller, 1982): como afirma Marx, essa relação "é evidentemente o resultado de um desenvolvimento histórico anterior, o produto de muitas revoluções [Umwälzungen] econômicas, da decadência de toda uma série de formações mais antigas da produção social" (K, I, 183; C.I, 1, 287).

12 Note-se ademais que Marx não considerava a circulação simples analisada no início de $O$ capital como uma fase histórica caracterizada pela produção generalizada, mas não capitalista, de mercadorias, mas antes como um momento da produção capitalista. Como ele escreve no Urtext (1974, p. 922) "Não se trata aqui (...) de uma passagem [Übergang] histórica da circulação ao capital. A circulação simples é muito mais uma esfera abstrata do processo global da produção burguesa, que se revela através de suas próprias determinações como momento, mera forma de aparecimento de um processo que transcorre por trás dela, [e que] de mesmo modo resulta dela (...) - o capital industrial". Ou, como se lê em $O$ capital: "O que (...) caracteriza a época capitalista é que a força de trabalho assume, para o próprio trabalhador, a forma de uma mercadoria que pertence a ele, que, por conseguinte, seu trabalho assume a forma de trabalho assalariado (...) a partir desse instante se universaliza a forma-mercadoria dos produtos do trabalho" (K, I, 184; C, I. 1, 288 nota). 
Que o possuidor de dinheiro encontre a força de trabalho no mercado, que o encontre nos limites da circulação como mercadoria: esse pressuposto, da qual nós aqui partimos, e da qual a sociedade burguesa parte em seu processo de produção, é obviamente o resultado de um longo desenvolvimento histórico, o resumé de muitos cataclismos [Umwälzungen], e pressupõe o declínio de outros modos de produção (relações sociais de produção) e determinados desenvolvimentos das forças produtivas do trabalho social. (...) Esse nivel de desenvolvimento histórico da produção econômica - cujo produto mesmo é o trabalho livre - é, porém, o pressuposto para o devir [Werden] e ainda mais para a existência [Dasein] do capital enquanto tal. Sua existência é o resultado de um demorado processo histórico nas configurações econômicas da sociedade (Marx, 2013, p. 33, tradução nossa).

Percebe-se, pois, que o reconhecimento do caráter limitado do método dialético é condição sine qua non da explicitação do fundamento histórico da lei do valor, essa lei despótica que só opera ali onde se encontram, "de um lado, possuidores de dinheiro e de mercadorias e, do outro, meros possuidores das próprias forças de trabalho" - uma relação que não é produzida pela natureza, e não é, portanto, comum a todos os períodos históricos (K, I, 183; C, I.1, 287).

Cabe notar, porém, que, uma vez constituído historicamente o modo de produção capitalista, a reprodução da força de trabalho deve ser considerada como um resultado da própria reprodução do capital. Como afirma Marx, se:

\begin{abstract}
os pressupostos (...) aparecem para o surgimento histórico do capital como pressupostos exteriores e dados, do mesmo modo, assim que o capital tenha se tornado capital enquanto tal, ele cria seus próprios pressupostos (...) através de seu próprio processo de produção. Esses pressupostos, que originalmente apareceram como condiçães de seu devir - e por isso ainda não podiam emergir de sua ação como capital - aparecem agora como resultado de sua própria realização, de sua efetividade (...) - não como condições de seu surgimento, mas como resultado de sua existência [Dasein]. Ele não parte mais de pressupostos, (...) mas sim é ele mesmo pressuposto, parte de si, cria os pressupostos de sua conservação e de seu crescimento mesmos (Marx, 1974, p. 372).
\end{abstract}

E, no entanto, a crítica da economia política também é capaz de revelar o caráter unilateralmente formal da subordinação de todos os elementos da sociedade ao movimento do valor em processo e, portanto, também o caráter contingente da relação do valor consigo mesmo - com o que ela demonstra que a autodeterminação do capital não pode ser plena, embora pareça sê-lo. Noutras palavras, a crítica da economia política desvenda não apenas os pressupostos históricos, mas também os limites insuperáveis do próprio modo de produção capitalista, os quais por sua vez determinarão o caráter da própria exposição conceitual. E assim ela recupera a dignidade do elemento propriamente histórico na consideração teórica do capital. 
Como afirma Fulda (1974, p. 210, tradução nossa), a exposição conceitual do capital:

não deve reduzir o elemento histórico [das Historische] a meros apontamentos. A conexão entre fenômeno e essência, que o método de desenvolvimento descobre, deve (...) tornar definiveis os pontos em que a exposição sistemática tem que ceder lugar à consideração histórica e nos quais deve ser corrigida a aparência de que se trataria somente de um desenvolvimento conceitual.

Assim, embora também em $O$ capital - como, aliás, em praticamente toda ciência social - o elemento histórico possa em certos casos servir à mera ilustração de uma relação já desenvolvida conceitualmente, ${ }^{13}$ na principal obra de Marx esse elemento realizará dois outros tipos de intervenção sobre a exposição lógico-sistemática. Em primeiro lugar, como já vimos, o elemento histórico pode aparecer como pressuposto da própria existência do objeto em consideração. Mas ele deve, além disso, intervir nos pontos além dos quais o desenvolvimento conceitual stricto sensu não pode ir (SGRO', 2009), como, por exemplo, na análise da determinação da taxa de mais-valor. Quando demonstra que a reprodução de uma economia capitalista implica, por um lado, a acumulação de capital, e, por outro, a reprodução da força de trabalho, a apresentação conceitual fornece os limites absolutos da taxa de mais-valor. ${ }^{14}$ A determinação da taxa efetiva, porém, depende de contingências históricas como o grau de desenvolvimento das forças produtivas, a capacidade de organização e de luta das diferentes classes sociais e de um elemento histórico e moral que distingue a determinação do valor da força de trabalho da determinação do valor das outras mercadorias. Sobre tais fatores, porém, o conceito enquanto tal tem muito pouco a dizer - o que significa que, a partir desse ponto, a exposição dialética deve dar passagem à análise histórica propriamente dita.

Em $O$ capital, portanto, a dialética não se apresenta como a forma de desenvolvimento da história presidido pelo desenvolvimento das determinações de um conceito; muito pelo contrário: "como 'método de processamento [Bearbeiten]' da Economia burguesa, (...) a dialética distingue-se" não apenas "da exposição de seu objeto", mas também de "sua consideração histórica” (Fulda, 1974, p. 210). Com efeito, na própria medida em que demonstra que superação conceitual da dualidade pressuposta pela

13 Veja-se, por exemplo, a quinta seção do capítulo 23 do livro I de $O$ capital. 14 Cf. os capítulos 7 e 8 do primeiro volume de $O$ capital. 
economia política não resulta na reconciliação dos momentos opostos, mas antes na elucidação do caráter violento dos processos de identificação que a sociabilidade capitalista executa à força (Marx, 1971, p. 45), a crítica da economia política nos induz a estabelecer uma clara distinção entre a apresentação conceitual das formas capitalistas e a história efetiva do capital. E assim ela não apenas assinala o caráter ilusório da representação - à qual a economia política, em suas mais variadas versões, reiteradamente sucumbe - da história como processo de realização progressiva e inevitável do capital, mas também convida os verdadeiros sujeitos desse processo a, finalmente, assumir o protagonismo que lhes cabe.

\section{Referências}

BACKHAUS, H. G. Der widersprüchliche und monströse Kern der nationalökonomischen Begriffsbildung. In: FETSCHER, I. (Ed.). Emanzipation als Versöhnung. Zu Adornos Kritik der 'Warentausch'- Gesellschaft und Perspektiven der Transformation. [S.1.] Neue Kritik, 2002.

BÖHM-BAWERK, E. Teoria positiva do capital. Trad. L. J. Baraúna. São Paulo: Nova Cultural, 1986.

FISHER, I. The nature of capital and income. [S.1.] CreateSpace Independent Publishing Platform, 2011.

FULDA, H. These zur Dialektik als Darstellungsmethode (im "Kapital" vom Marx). In: HegelJahrbuch. Köln: Pahl-Rugenstein Verlag, 1974.

GRESPAN, J. A crise na crítica à economia política. Crítica Marxista, v. 10, p. 94-110, 2000.

GRESPAN, J. O negativo do capital. São Paulo: Expressão Popular, 2012.

HEGEL, G. W. F. Phänomenologie des Geistes. Paderborn: Voltmedia Gmbh, 2005.

HEINRICH, M. Die Wissenschaft vom Wert: Die Marxsche Kritik der politischen Ökonomie zwischen wissenschaftlicher Revolution und klassischer Tradition. 5. Auflage ed. Münster: Westfälisches Dampfboot, 2014.

HORKHEIMER, M. Traditionelle und kritische Theorie. Disponível em: <http://lesekreis. blogsport.de/images/MaxHorkheimerTraditionelleundkritischeTheorie.pdf $>$. Acesso em: 15 nov. 2017.

MARX, K. Das Kapital: Kritik der Politischen Ökonomie. Hamburg: O. Meissner, 1867.

MARX, K. MEW Band 13, Zur Kritik der Politischen Okonomie. Berlim: Dietz Verlag, 1971.

MARX, K. MEW Band 4, Das Elend der Philosophie. Berlim: Dietz Verlag, 1972.

MARX, K. Grundrisse der Kritik der politischen Ökonomie (Rohentwurf). 1857-1858, Anhang 18501859. 2. ed. Berlim: Dietz Verlag, 1974.

MARX, K. O capital: crítica da economia política. (Livro Primeiro, v. I). Trad. F. Kothe. São Paulo: Nova Cultural, 1983a. 
MARX, K. O capital: crítica da economia política. (Livro Primeiro, v. 2). Trad. F. Kothe. São Paulo: Nova Cultural, 1983b.

MARX, K. O capital: crítica da economia política. (Livro Terceiro, v. I). Trad. F. Kothe. São Paulo: Nova Cultural, 1985a.

MARX, K. O capital: crítica da economia política. (Livro Terceiro, v. II). Trad. F. Kothe. São Paulo: Nova Cultural, 1985 b.

MARX, K. Manuscritos econômico-filosóficos e outros textos escolhidos. Trad. J. C. Bruno. São Paulo: Abril Cultural, 1985c.

MARX, K. MEW Band 29, Briefe Januar 1856 - Dezember 1859. Berlim: Dietz Verlag, 1987.

MARX, K. MEW Band 24, Das Kapital, Buch II. 11. ed. Berlim: Dietz Verlag, 2003.

MARX, K. MEW Band 25, Das Kapital, Buch III: Der Gesamtprozess der kapitalistischen Produktion. $15^{\text {a }}$ ed. Berlim: Dietz Verlag, 2004.

MARX, K. MEW Band 23, Das Kapital, Buch I. 21. ed. Berlim: Dietz Verlag, 2005.

MARX, K. MEW Band 26/3, Theorien über den Mehrwert. Berlim: Dietz Verlag, 2008a.

MARX, K. MEW Band 26/2, Theorien über den Mehrwert. Berlim: Dietz Verlag, 2008b.

MARX, K. O 18 de brumário de Luís Bonaparte. Trad. N. Schneid. São Paulo: Boitempo Editorial, 2011.

MARX, K. Zur Kritik der Politischen Ökonomie (Manuskript 1861-1863). Berlim: Walter de Gruyter, 2013.

MÜLLER, M. Exposição e método dialético em "O capital”. Boletim Seaf, n. 2, Belo Horizonte, 1982.

REICHELT, H. Zur logischen Struktur des Kapitalbegriffs bei Karl Marx. Frankfurt a.M.: Europäische Verlagsanstalt, 1973.

REICHELT, H. Neue Marx-Lektüre: zur Kritik sozialwissenschaftlicher Logik. Hamburg: VSAVerlag, 2008.

RICARDO, D. Princípios de economia política e tributação. Trad. P. H. R. Sandroni. São Paulo: Abril Cultural, 1982.

RUBIN, I. I. Essays on Marx's Theory of Values. Delhi: Black Rose Books, 2008.

SGRO', G. Die dialektisch-materialistische Methode der Marxschen Kritik der politischen Ökonomie. Stichworte zu einer unendlichen Geschichte. In: MÜLLER, S. (Ed.). Probleme der Dialektik heute. Wiesbaden: VS Verlag für Sozialwissenschaften, 2009, p. 201-228.

SRAFFA, P. Introdução. In: RICARDO, D. Princípios de economia política e tributação. Os economistas. Trad. P. Sandroni. São Paulo: Abril Cultural, 1982.

THEUNISSEN, M. Crise do poder: teses para a teoria da contradição dialética. Cadernos de Filosofia Alemã: Crítica e Modernidade, v. 24, n. 1, p. 183-196, 27 jun. 2019.

THEUNISSEN, M. Sein und Schein. Die Kritische Funktion der Hegelschen Logik. Frankfurt am Main: Suhrkamp, 1994.

WOLF, D. Semantik, Struktur und Handlung im "Kapital". Disponível em: <http://dieterwolf. net/wp-content/uploads/2016/02/Semantik_Struktur_und_Handlung_im_Kapital.pdf>. Acesso em: 23 mar. 2017. 


\section{Sobre o autor}

Bruno Höfig -bhofig@gmail.com

SOAS, Universidade de Londres, Londres, Inglaterra.

ORCID: https://orcid.org/0000-0002-5937-1522.

O autor registra seus agradecimentos a um parecerista anônimo, por suas valiosas sugestões, e a Jorge Grespan e Leonardo Paes Müller, pela leitura crítica de diferentes versões deste texto. Os erros remanescentes, obviamente, são de nossa inteira responsabilidade.

\section{Sobre 0 artigo}

Recebido em 05 de fevereiro de 2018. Aprovado em 26 de junho de 2018. 